http://www.jfas.info

\title{
UHF RFID SPLIT RING RESONATOR-BASED TAG ANTENNA WITH PHOTONIC BANDGAP STRUCTURE FOR METALLIC OBJECTS
}

\author{
F. Erman ${ }^{1}$, A. Ismail ${ }^{1, *}$, R. S. A. R. Abdullah ${ }^{1}$, A. R. H Alhawari ${ }^{2}$, A. Shabaneh ${ }^{2}$ and N. \\ Mohamed $^{2}$
}
${ }^{1}$ Department of Computer and Communication Systems Engineering, Faculty of Engineering, Universiti Putra Malaysia, Serdang, Selangor, Malaysia
${ }^{2}$ Department of Electrical Engineering, College of Engineering, Najran University, 1988 Najran, Saudi Arabia

Published online: 10 September 2017

\begin{abstract}
Several recent works highlighted that metamaterial-based antennas are capable to function similar to large printed antennas. This paper presents a novel split-ring resonator-based UHF RFID tag antenna with photonic bandgap structure on metallic objects for high gain, which consists of two symmetrical C-shaped resonators with outer strip lines to feed split-ring resonator structure through implementing an inductively coupled feed approach placed on the top surface of Polytetrafluoroethylene substrate. The simulation results were verified by the presented method via enhancing the performance of tag antennas for metallic object.
\end{abstract}

Keywords: photonic bandgap (PBG);radio frequency identification (RFID);split-ring resonator (SRR)-based antenna.

Author Correspondence, e-mail: alyani@upm.edu.my

doi: http://dx.doi.org/10.4314/jfas.v9i3s.49 


\section{INTRODUCTION}

In recent years, RFID system has been widely applied in the ultra-high frequency (UHF) band [1]. It is used in inventory system, supply chain management, warehousing, service logistics and general detection system [2]. RFID interrogator and a passive tag antenna are consisted a typical RFID system [3]. Improving the operation power of the chip is depended on achieving an excellent impedance matching between tag antenna and IC chip thus increasing the gain.

The ability of placing modern RFID tag antennas on metallic objects has been investigated [4-11]. The most challenging issue is designing tag antenna for metallic objects with high gain, little reflection coefficient and small size. Metamaterial-based antennas are capable of equally exhibiting similar characteristics seen in large antennas. Therefore, it minimizes the size and enhance the gain are the benefit of using metamaterial-based antennas. PBG structure is integrated in the design to achieve further gain.

In this paper, a compact microstrip RFID tag antenna reported for metallic objects using SRR-based antenna with PBG structure to achieve a better gain at its operating frequency of $923 \mathrm{MHz}$.

\section{RESULTS AND DISCUSSION}

The performance of RFID tag antenna design was analysed using full-wave electromagnetic simulator [12]. Tuning of the presented tag antenna performance was studied by placing the RFID tag antenna on a square perfect electrical conductor (PEC) of $200 \mathrm{~mm}$ side length, while the thickness of PEC is $1 \mathrm{~mm}$. The proposed tag antenna used a Murata RFID MAGICSTRAP LXMS31ACNA-011 tag chip [13]. The input impedance of the RFID tag chip is $25-\mathrm{j} 200 \Omega$ at its operating frequency $915 \mathrm{MHz}$ with $-8 \mathrm{dBm}$ a minimum $\mathrm{RF}$ communication power of the tag chip.

The resonance frequency of the proposed tag antenna shifted up when the PBG structure integrated with the design. Fig. 1 shows the different in the resonance frequency between SRR-based tag antenna with regular ground and PBG ground. 


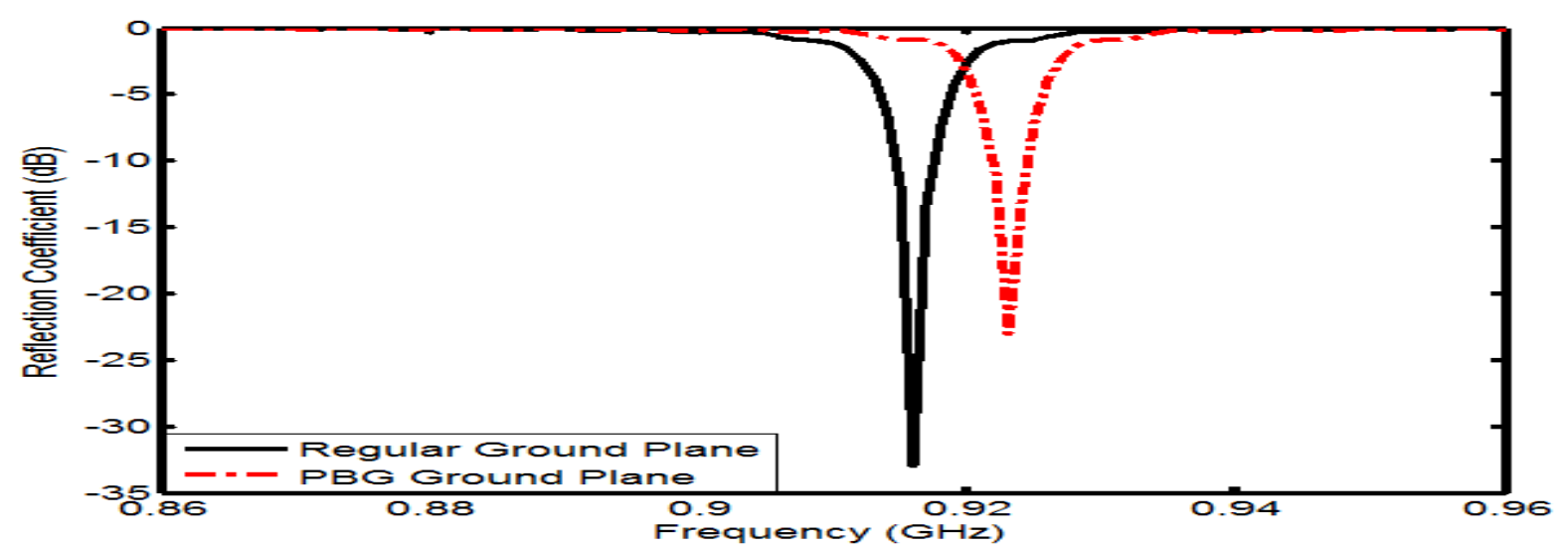

Fig.1. The resonance frequency of the proposed designs

The input resistance and reactance of the tag antenna with PBG structure is equal to $18.5+\mathrm{j} 192.8 \Omega$, which is in good compliance with the input impedance of IC chip curves at its resonance frequency $923 \mathrm{MHz}$ as shown in Fig. 2.

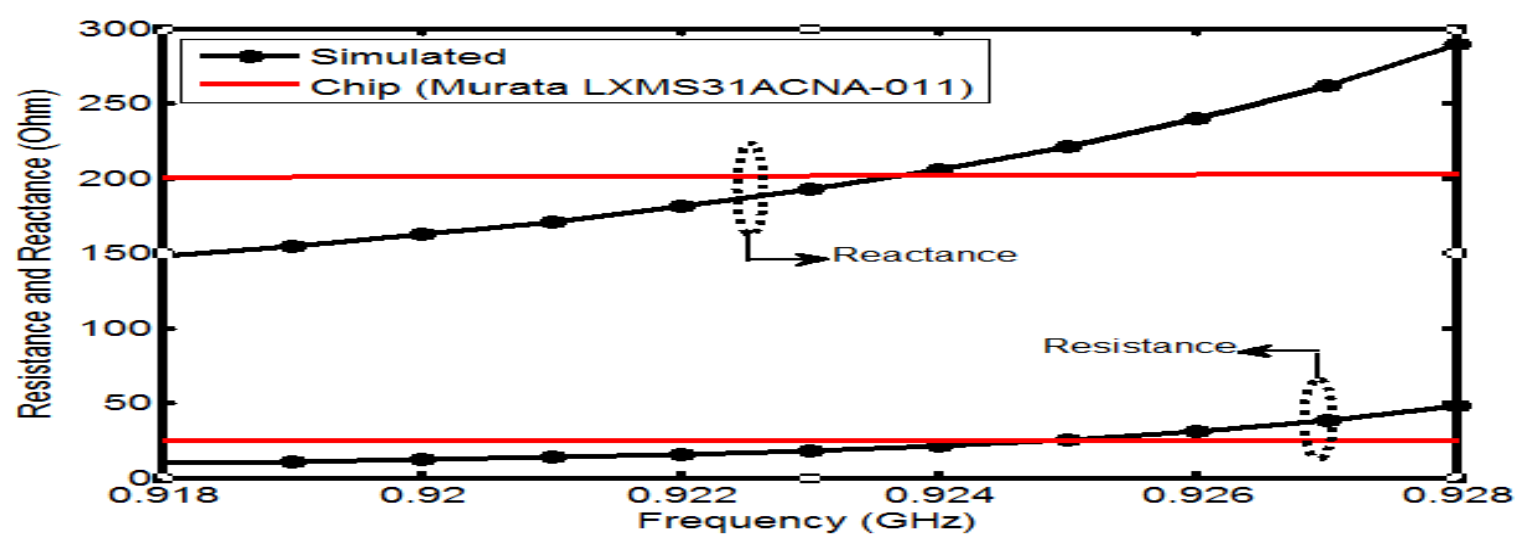

Fig.2. The complex impedance of the proposed antenna with PBG ground plane.

The simulated gain for different metal plates of various sizes are used to mount the proposed design with PBG ground plane on the top surface as shown in Fig. 3. In this figure, the gain performance obvious enhances slightly when the ground surface size increased above $200 \times 200 \mathrm{~mm}^{2}$.

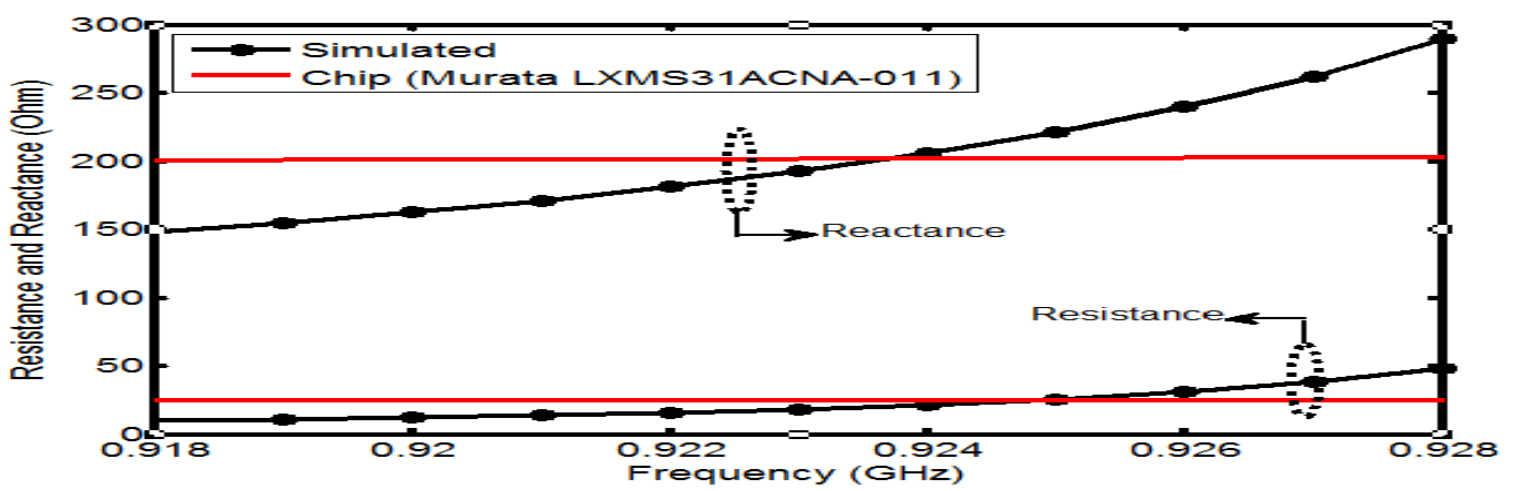

Fig.3. The complex impedance of the proposed antenna with PBG ground plane 
The simulated gain for different metal plates of various sizes are used to mount the proposed design with PBG ground plane on the top surface as shown in Fig. 3. In this figure, the gain performance obvious enhances slightly when the ground surface size increased above $200 \times 200 \mathrm{~mm}^{2}$.

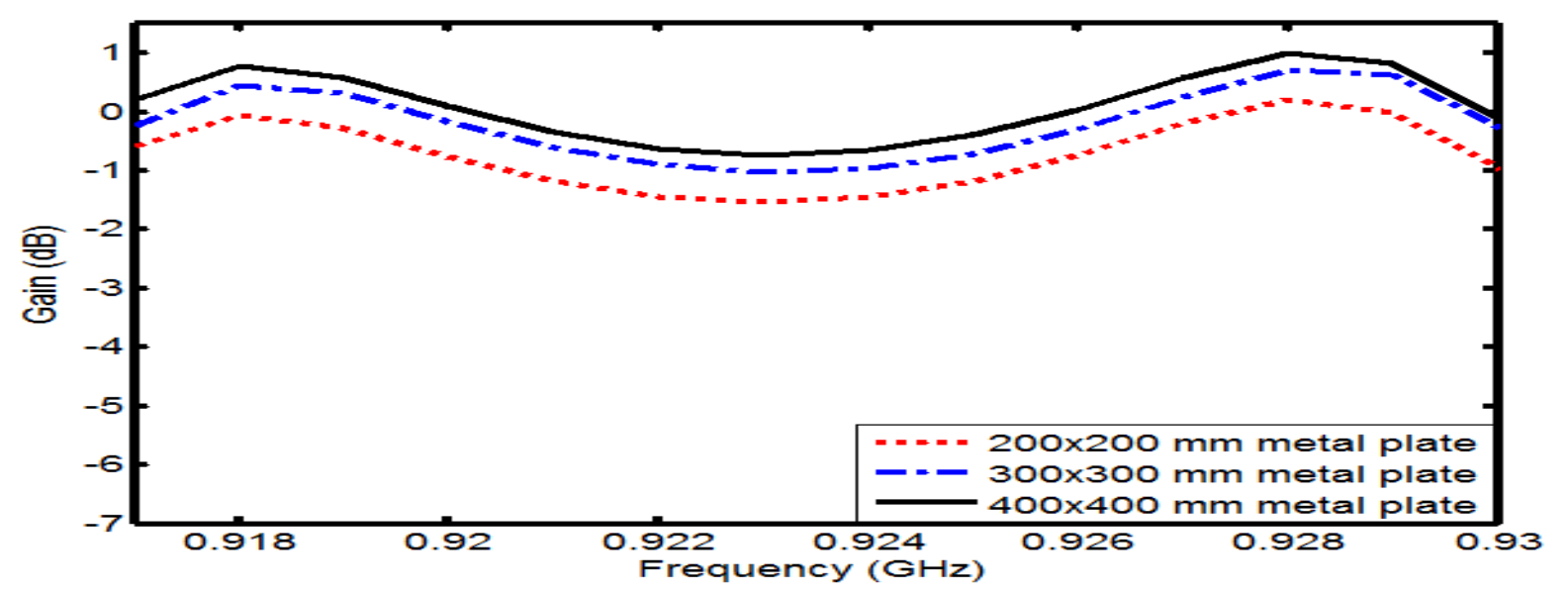

Fig.4. Simulated gain of the proposed design with PBG ground plane placed on various metal plate sizes

\section{EXPERIMENTAL}

The presented SRR-based tag antenna as shown in Fig. 5 is fabricated on low-cost Polytetrafluoroethylene (PTFE) substrate with dielectric constant of $\left(\varepsilon_{\mathrm{r}}\right) 2.55$, loss tangent ( $\tan$ $\delta=0.001)$ and thickness equalling $1.5 \mathrm{~mm}$.

The presented RFID tag antenna comprises of two symmetrical C-shaped resonators with outer strip lines to feed the split-ring resonator structures through implementing an inductively coupled feed approach placed on the top planer of Polytetrafluoroethylene substrate. The outer strip line is added to improve the overall performance of reflection coefficient through attaining a conjugate match between antenna and RFID tag chip. 


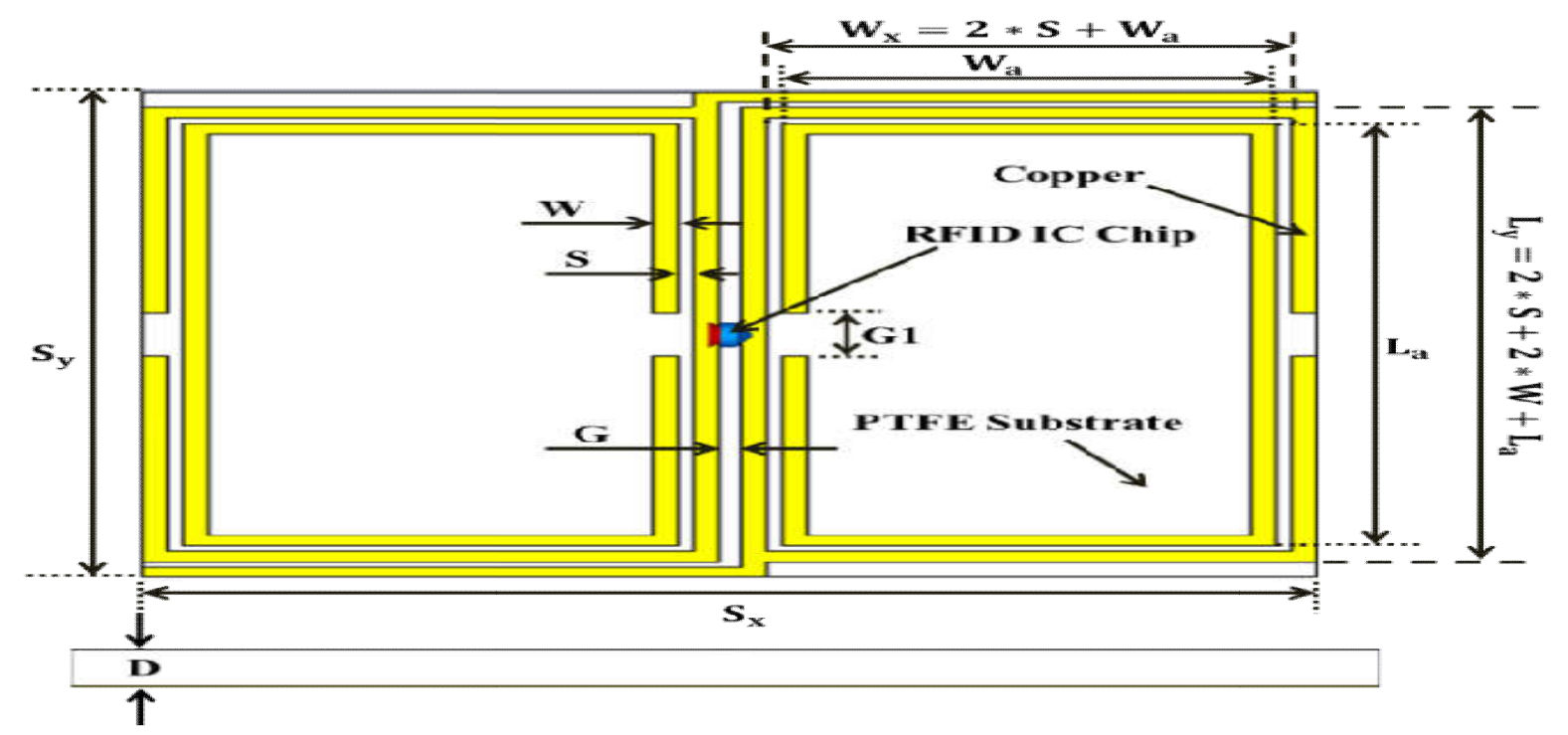

Fig.5. Geometry of the presented tag antenna, $\mathrm{S}_{\mathrm{x}}=62.8, \mathrm{~S}_{\mathrm{y}}=83.7, \mathrm{D}=1.57, \mathrm{~W}=0.5, \mathrm{~S}=0.2$,

$$
\mathrm{G}=0.5, \mathrm{G} 1=2, \mathrm{~L}_{\mathrm{a}}=60, \mathrm{~W}_{\mathrm{a}}=40.2 \text { (unit: } \mathrm{mm} \text { ) }
$$

Through etching a periodic pattern of circles in the ground plane of tag antenna can be formed a simple PBG structure. Fig. 6 presents the PBG structure, which is integrated in the design to improve the gain of the design. The circular slots diameter and the dimension between the circular slots are $5 \mathrm{~mm}$ and $2 \mathrm{~mm}$ respectively.

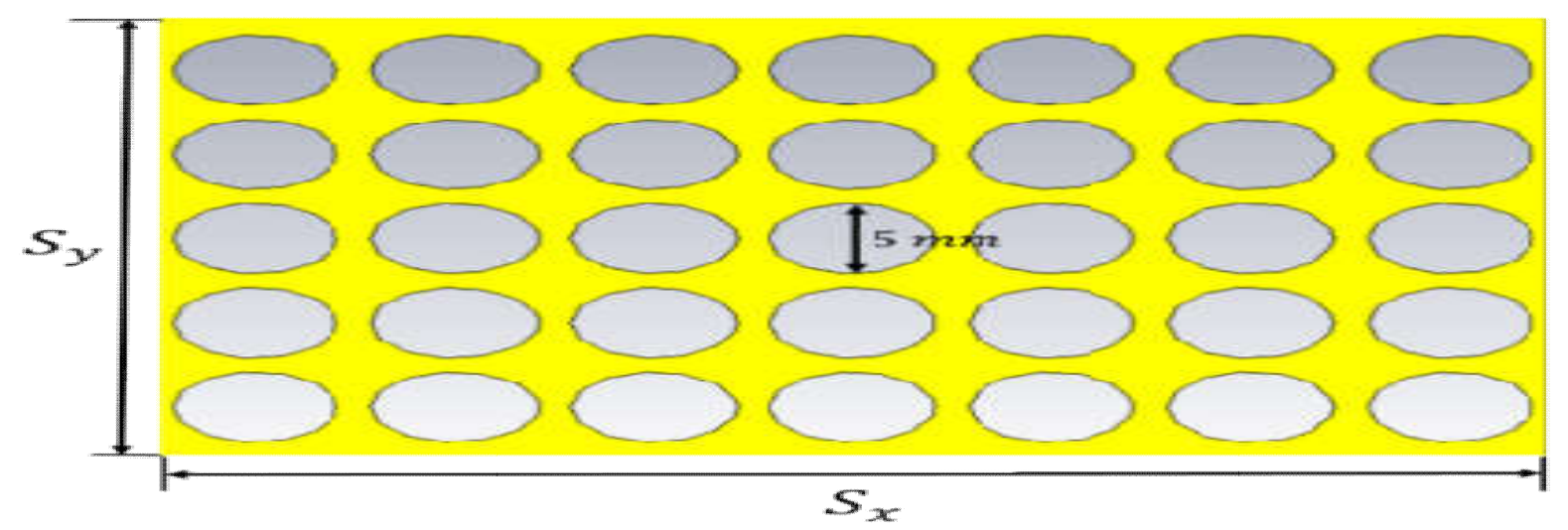

Fig.6. PBG structure

\section{CONCLUSION}

The SRR-based UHF RFID tag antenna integrated with PBG structure fed by a symmetrical C-shaped resonator using inductively coupled feed structure, which has been reported and simulated. The proposed feeding technique and PBG structure offer a better performance of RFID [14] tag. The advantage of the reported symmetrical C-shaped feed structure offers a 
simple solution to an efficaciously method to conjugate the input impedance between tag antenna and IC chip. The simulation results have verified that the presented method is able to improve the performance of tag antennas for metallic objects.

\section{REFERENCES}

[1] Chen S, Chen Y, Li H J. A novel dual-antenna structure for UHF RFID tags. IEEE Transactions on Antennas and Propagation, 2011, 59(11):3950-3960

[2] Finkenzeller K. RFID handbook: Radio-frequency identification fundamentals and Applications. New York: Wiley, 2004

[3] Travassos X, Lisbao A, Vieira D. Design of meander-line antennas for radio frequency identification based on multiobjective optimization. International Journal of Antennas and Propagation, 2012, 1(2):10-17

[4] Kamalvand P, Pandey K G, Meshram K M, Mallahzadeh A. A single sided dual-antenna structure for UHF RFID tag applications. International Journal of RF and Microwave Computer-Aided Engineering, 2015, 25(7):619-628

[5] Pan T, Zhang S, He S. He. Compact RFID tag antenna with circular polarization and embedded feed network for metallic objects. IEEE Antennas and Wireless Propagation Letters, 2014, 13:1271-1274

[6] Chen H D, Kuo S H, Jheng J L. Design of compact circularly polarized radio frequency identification tag antenna for metallic object application. Microwave and Optical Technology Letters, 2013, 55(7):1481-1485

[7] Chen H D, Sim C Y D, Kuo S H. Compact broadband dual coupling-feed circularly polarized RFID microstrip tag antenna mountable on metallic surface. IEEE Transactions on Antennas and Propagation, 2012, 60(12):5571-5577

[8] Chen H D, Kuo S H, Sim C Y D, Tsai C H. Coupling-feed circularly polarized RFID tag antenna mountable on metallic surface. IEEE Transactions on Antennas and Propagation, 2012, 60(5):2166-2174

[9] Bashri M S R, Ibrahimy M I, Motakabber S. Design of a planar wideband patch antenna for UHF RFID tag. Microwave and Optical Technology Letters, 2014, 56(7):1579-1584 
[10] Yang E S, Son H W. Dual-polarised metal-mountable UHF RFID tag antenna for polarisation diversity. Electronics Letters 2016, 52(7):496-498

[11] Yasumitsu B, Manabu K. Design of a UHF RFID tag antenna to keep the read range constant between on and off metal. In IEEE International Symposium on Antennas and Propagation, 2016, pp. 943-944

[12] Computer Simulation Technology (CST). Microwave studio version 2010. Darmstadt: CST, 2010

[13] Murata Manufacturing Co. Ltd (MMCL). Murata MAGICSTRAP ®application note. Kyoto: MMCL, 2012

[14] Aris MA, Kadir EA, Zain MY, Rizman ZI, Husin NH. A miniature UHF rectangular microstrip RFID tag antenna for aluminium can application.World Applied Sciences Journal, 2013, 23(23):96-102

\section{How to cite this article:}

Erman F, Ismail A, Abdullah R S A R, Alhawari A R H, Shabaneh A, Mohamed N. Uhf rfid split ring resonator-based tag antenna with photonic bandgap structure for metallic objects. J. Fundam. Appl. Sci., 2017, 9(3S), 630-636 